\title{
INFORMALITY IN FORMAL SPACES THROUGH SELF ORGANIZATION: A STUDY OF THE PEOPLE'S PROCESSES IN PUTTALAM TOWN IN SRI LANKA
}

\author{
PATHIRANA. H.P.W.P ${ }^{1} \&$ MUNASINGHE. J² \\ 1,2 Department of Town and Country Planning, Faculty of Architecture University of Moratuwa, Sri Lanka \\ ${ }^{1}$ wishmipiumika@gmail.com, ${ }^{2}$ jagathnm@uom.lk
}

\begin{abstract}
Informality is an inevitable ingredient in an urban environment. The 'formally' established urban built environments are informally shaped by people for the appropriation of spaces for their activities. Within dominant institutionalized urban planning processes, such informalities are often regarded as 'nuisances', 'out-of-place', and 'misfits' in urban spaces. Yet, informally organized spaces are as important as formal spaces for the vitality, equity, and sustainability of all types of urban environments. People's processes in the creation and operation of informal spaces, resisting, contesting, and negotiating the dominant formal networks, have been the subject of many scholarly works over the last few decades, but a lack of empirical work and informative case studies on the subject has distanced mainstream planners and urban designers from learning and integrating such informal space production into institutionalized urban development processes. In order to mend this gap and reorient the prevalent understanding among planning professionals, a people's endeavor in Puttalam town in Sri Lanka to form and sustain informal spaces is presented in this paper. The paper elaborates on the 'self-organizing' behaviour of the small-scale retail vendors and the day-to-day users of the city to withstand interventions by the authorities on the public market space of the town.
\end{abstract}

Keywords: Informal spaces, formal spaces, people's process, self-organization

\section{Introduction}

In present day context, institutionalized urban development activities carried out by the planners and professionals are generally understood as the formal mode of production of space (Douglas, 1966, p. p.02; Lofland, 1973). Besides such formal processes, ordinary local inhabitants frequently produce and reproduce a variety of spaces along with the authorities and professionals (Perera, 2016), and adapt and transform formal spaces to best suit their purposes (Lefebvre, 1991). This process of appropriation, reshaping of formal urban spaces has directly led to the production of 'informal' spaces in 'planned' and 'designed' urban environs. While these informal spaces are regarded as "social breathing spaces" (Shaw \& Hudson, 2009), vital in urban composition (Dovey, 2012), represent "everyday life" (Lefebvre, 1991) and provide an umbrella of opportunities for ordinary people (Perera, 2016; Babere, 2015). But there are others those were critical about informal spaces as "dirt out of place urban element" (Cresswell, 1996), which appear as spaces of "disruptive", "nuisance" (Nasar, 1998) "homeless shelters" (Yatmo, 2008) and graffiti (Cresswell, 1996) in the formal environments. The formation of informal spaces for vending, trading, parking, and gathering in and around planned spaces has become frequent and common experience in all big and small urban areas in Sri Lanka. The case of people's processes involved in the production of informal spaces in a formal urban built environment in Puttalam town in Sri Lanka, is presented in this paper to serve two timely requirements in the fields of urban planning and urban design. The first is related to the planning and designing of urban environments, where urban development plans conventionally frame urban spaces as static end products in the city context, envisaging a sanitized built environment with permanent structures and perpetual spaces (Ellickson, 1996). They pay less or no regard towards the important vitality contributed by the informal interventions by the inhabitants. The Second is related to their implementation, where the said plans intend to accomplish the envisaged formality and to maintain an idealized order by cording them into rigid policy guidelines, planning and 
building regulations (Talen, 2016; Perera, 2016). These rigidities outlaw the role of the uses in vitalizing spaces in urban areas. However, inadequate understanding of these limitations leads urban plans not only to fail in delivering the expected outcomes, but also to result in unexpected circumstances. Examples are abundantly found in Sri Lanka in its urban areas.

\section{The Objective and the Research Approach}

In the above situation, the objective of this paper is to contribute towards the enhancement of awareness among planners and urban designers on said limitations inherent to existing urban development processes by analytically studying a real ground case from the Sri Lankan context. For that purpose, the paper adopts the metaphor of a 'self-organizing system' that consists of multiple agents, their inter-relations, organized in a broader 'environment' for its sustenance and evolved through resistance, contestations, adaptations and internal adjustments, amidst evolving conditions of both the internal and external environments.

\section{Preceding Studies}

The informal assemblage of activity spaces in urban areas is mostly regarded as illegible and a nuisance within dominant urban development discourse, despite the fact that they are produced out of the abstract city order by ordinary people as part of their daily lives (Yatmo, 2008).In city plans, they are also situated outside the formal zones of use and occupation, despite their existence somewhere between the official commercial, recreational, and residential zones of the city (Shaw \& Hudson, 2009) and appear in the form of informal vending, parking, trading, hawking, begging, advertising, gathering, and illegal activating spaces in the formal environments.

Yamato (2008), in her empirical research, explains how street vending spaces have been informal, out of place urban elements in Indonesian formal urban environments. She explains these informal vending space production processes as a result of social differentiation and segregation. Street vendors represent the poor and powerless actors in society, and they have limited rights and access to the formal urban spaces in the cities. Then they organize as a whole and reshape informal vending spaces along with formal environments, while contesting and conflicting with formal spaces. In Jakarta, Indonesia, the whole street vendor population (83\%) operates in illegal locations while only $16.6 \%$ occupy those that are legal spaces (Yatmo, 2008).

Soja (1996) has developed on Henry Lefebvre's (1991) social production of space, introduced the concept of trialectics of being, where he explained space was constructed through a combination of the location, local and the sense of place. "Location refers to the geographical and material setting of the place. The social and cultural relationships were interpreted by Locale Sense of place is the meaningful spaces which are built by the people according to their behavior. Race, gender, sexuality, language, subcultures, social and cultural relationships are the main aspects of creating a meaningful space. Those three components make a meaningful place". (w.Soja, 1996)

Perera (2016) has studied "space-making processes of four ordinary social actors such as emergent spaces, familiarization, feminization, and indigenization in late 19th-century Colombo, the former capital of Ceylon", and argues that between and besides official place-making, ordinary people produce more quantity and variety of spaces than the authorities and professionals to influence cultural and social relationships. When abstract spaces are imposed on local people, they adapt, create, recreate, reshape, and negotiate to transform spaces to best suit their purpose. Those spaces produced by weaker subjects are illegible for authorities, professionals, and planners and therefore, named 'lost spaces' (Perera, 2016). Yet, ordinary people have purposes in them and these are acts, therefore, are 'appropriations' rather than 'violations. This dichotomy was the subject of Brendah Yeoh's (2000) work, on 'contested spaces' in colonial Singapore. In this work she explains how various interests in the same urban space by different groups result in both apparent and latent conflicts among such interests and thus lead to the reshaping of the same space to cater to different needs. The space contestation and negotiation process that enabled the small towns in Sri Lanka to evolve into their present-day forms was studied by Munasinghe (2012), inferring the dynamics of self-organizing systems. This application can be used to better understand the never-ending conflicts between the planning and enforcing officials and the everyday occupiers of the city space in most Sri Lankan towns. The flow of the case presented in this paper is developed based on this concept.

\section{Self-Organizing Systems}


Self-organization is explained as an organic process in which mutual interactions between the internal agents of a given system enable it to settle a chaos that it is undergoing with a spontaneous order exhibited in its environment (Roo, 2016). The process can be spontaneous when sufficient energy is available within the system, not needing control by any external agent. It is often triggered by seemingly random fluctuations, amplified by positive feedback. The resulting organization is wholly decentralized, distributed over all the components of the system. As a result, the organization is usually robust and capable of surviving or self-repairing significant perturbation (Ashby, 2004).

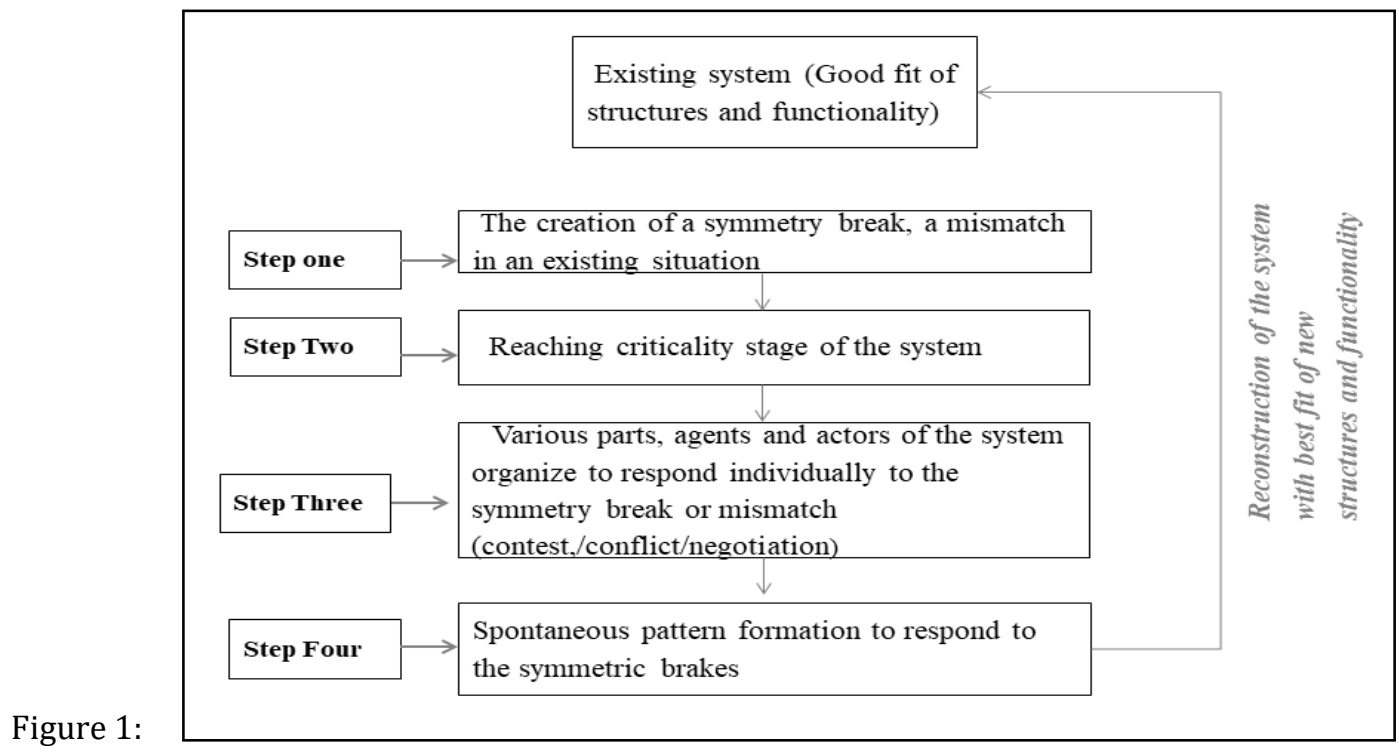

Framework of process of the self-organization (Source: Rooi (2016))

Rooi's

Three essential attributes are identified in a self-organizing system; context, external agents, internal agents. (Portugali , 1997; Munasinghe, 2012; Ashby, 2004). The internal agents in a given system are organized in strictures that are produced by them and those structures in turn, enable the sustenance of the agents. When external agents (forces of change) intervene or disturb the structures or parts of them, produced by the internal agents of a system, unless the system is totally collapsed, the internal agents reorganize either to reproduce the existent structures or to create new structures while contesting, absorbing, and negotiating the conditions imposed by external agents (Munasinghe, 2012; Ashby, 2004). In present day urban context, the street vendors, ordinary inhabitants of the city, and the other associated groups resonate the role of the internal agents of a self-organizing system. They are in a process of negotiating with each other and have settled on their transactions. These transactions are facilitated through the appropriation of spaces provided within the broader formal spaces of the city. Such appropriation provides the enabling environments for these organically evolved systems to sustain themselves. The government authorities, planning agencies, and professionals who intervene in certain planning and design strategies to maintain the formal order of the city, conceived with their ideologies, can be conceptualized as external forces. When those interventions Change organically evolved patterns of urban activities or impact on the supportive environment, then the internal agents of the particular urban system would first resist and then contest and finally negotiate to adapt by means of reorganizing themselves.

This adaptation manifests itself as reshaping or reproducing existing environments or constructing new structures by contesting, negotiating in response to external force of changes. These Selforganizing processes mostly produce another form of informal spaces in the formal environments and their self-organization system operates with the self-build unique patterns which represent their requirements in the formal environments.

\section{The method of study}

To understand the formation of informal spaces in formal environments in light of self-organization, the formal market of the Central public market area and the public bus stand area in Puttalam town in Sri Lanka were selected. The study preferred the case study approach due to the nature of investigation and the 
qualitative information involved in the inquiry. The inquiry process was supported by retrospective narrations of the vendors, citizens, and officials; written accounts available from the institutions; pictorial illustrations and news articles of the relevant events; and detailed ground observations made by the authors. All observations and statements were categorized and interpreted under key themes as phenomenological narratives and used to build up the story line of the evolution of space. The sequence of events is arranged to reflect Rooi's (2016) four steps of self-organizing, commencing from what the space looked like at the early stages and how its actors got organized in a self-contained operational system for harmonious transactions among them. The state of harmony observed at the beginning of events subject to this study, is benchmarked as the initial stage of self-organization. Then it divulges major events that interrupted the harmonious state of affairs in the urban space, reflecting upon the confrontational, compromising, and consensual situations recorded throughout, and the parties actively engaged in them. The consequent changes in the physical environment as the outcome of such situations are construed to manifest the new self-organized state of the system.

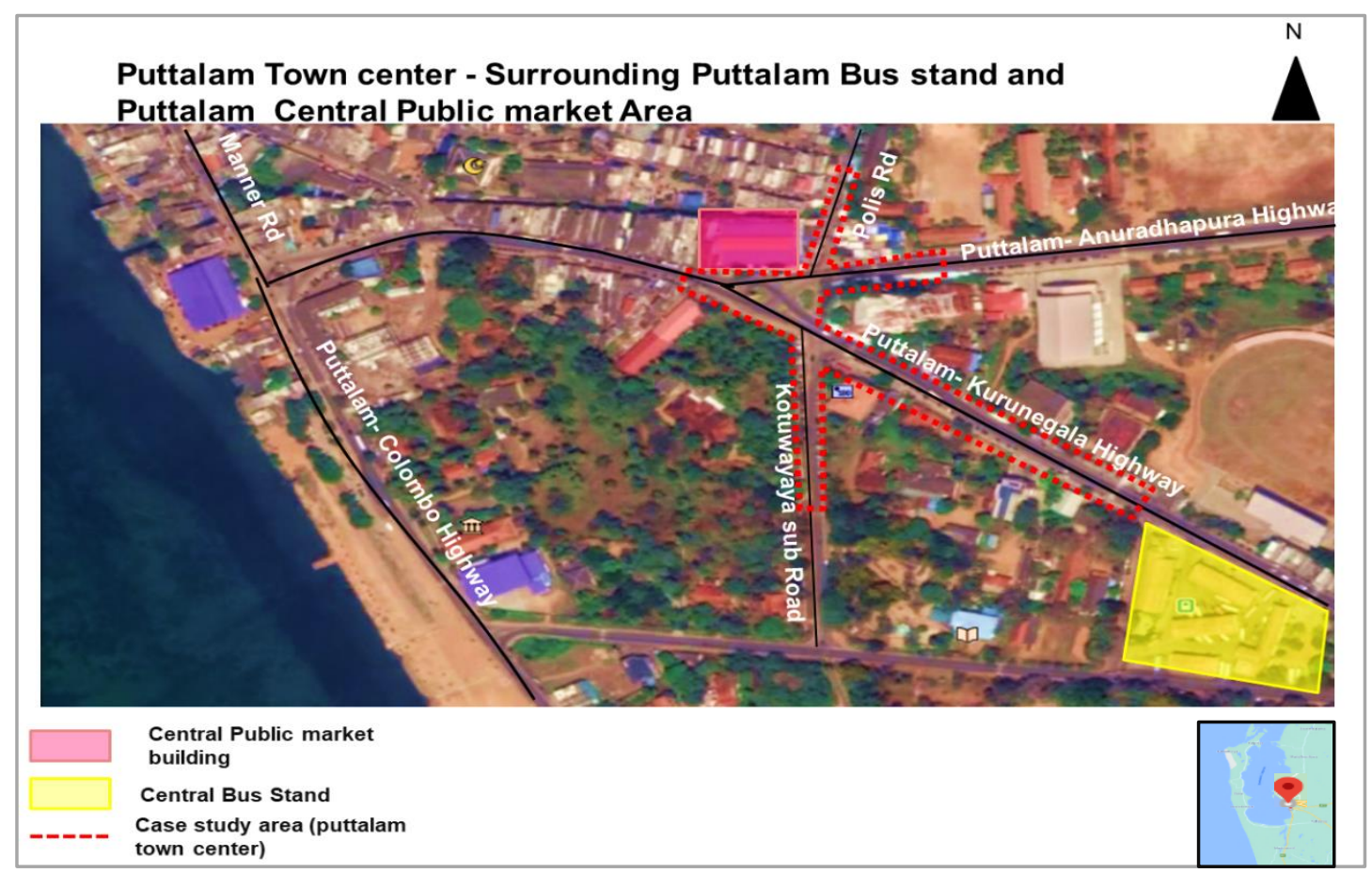

Figure 2: The location map of Puttalam Public Market

(Source: Google image, compiled by the Author 2020)

\section{The sequence of events}

\subsection{THE FIRST STAGES OF PUTTALAM POLA SPACE}

Before the 1980s, Puttlam town had a large open ground at the middle of the town center, owned by the government and used for multiple uses such as playground for youth and children, horse and bullock cart racing, and for special celebratory events. Throughout the week, the edges of this open space were occupied by footloose vendors selling fruits and vegetables. In 1984, these street vending activities were formalized by the urban council by providing them with some semi-permanent open structures, at the corner of the ground near the road intersection. These structures got replaced by a few larger open permanent structures in September 2011 by the urban council established and got established as the Pola (daily fare) of the town. The permanent buildings on the premises were gradually surrounded by many fragile structures such as extended shelters with polymer sheets, tin sheets, gunny sacks, and tents on open ground. Even though such arrangements were organic and did not follow a pre-planned design program, through these temporary add-ons to the formal physical arrangement provided by the council, the vendors and the patrons were finding comfort in operationalizing their transactions. This Pola ground was the center of the informal economy of the Puttalam town and the trading space for a small-scale trading community. 


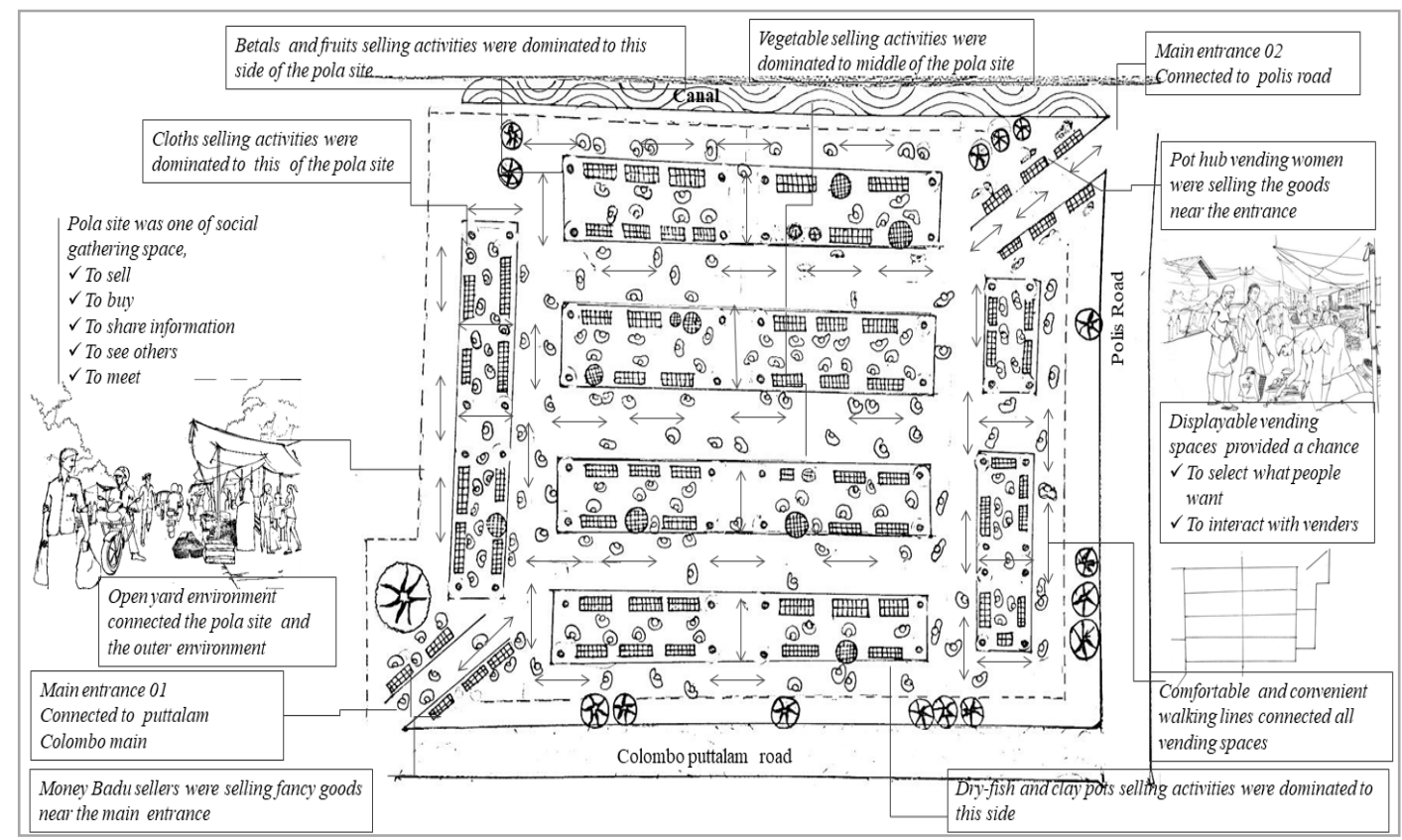

Figure 3: Pola as a people's place

(Source: compiled by author 2020, based on interviews)

It was recorded and informally confirmed by those who experienced the space that there were around twenty three vendors operating stalls, in addition to footloose sellers. The usual times of operation were from 6.00 am to until $10.00 \mathrm{pm}$. The formal and functional limits of the Pola were demarcated by the usually busy and crowded intersection of Puttalam-Anuradhapura road, Puttalam-Kurunagala road, and Puttalam-Colombo road. The internal arrangement, irrespective of the irregularity apparent in its physical apparatus, and in its layout, was a configuration of space that was highly responsive to the needs of both the vendors and patrons. It had conveniently identifiable entrances and exits, inter-connected lane spaces, and a mutually agreed interface between the vendors' space and the patrons' space. Previous pola site was formed by the vendors in their convenient way through the unique self-built structures which were dominated the temporal installments. Some vendors built the temporary vending spaces using the tin, huts, sacks, and wood stands among those halls. The displayable vending spaces, high interacted walking lines, open yard spatial configuration pattern, and convenient entrance with high connectivity to the outer environment were highly dominated physical characteristics for the efficient functionality of the pola site.

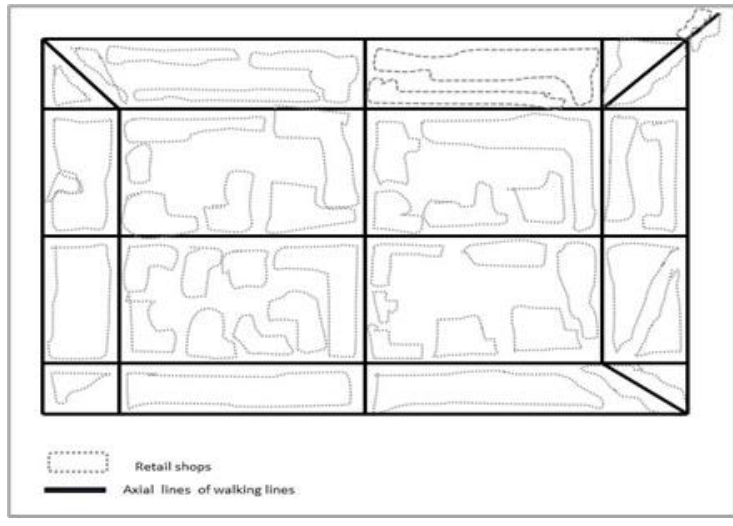

Figure 4: The Axial map of vending stall segments

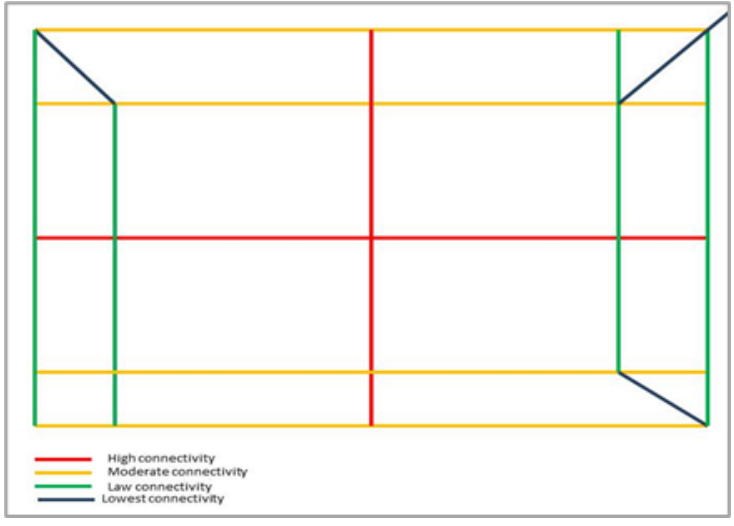

Figure 5: The Axial map of connectivity line in the pola site

(Source: compiled by author 2020, based on interviews)

The transactions between the parties were based on various commodities such as vegetables, fruits, clothes, fancy goods, etc. and small-scale service operations such as shoe repairs, sooth saying, etc. There were no records of conflicts in operations due to mutually agreed arrangements. Although the competition among vendors was inevitable, the friendship, unity and the sense of community maintained the essential attributes of harmonious market operations within the Pola space. The goods were delivered 
by the wholesale suppliers in the early hours of the morning to the retail sellers. The vendors arranged commodities in the open structures in a manner that buyers could exercise their limited-but free choices in a wider display.

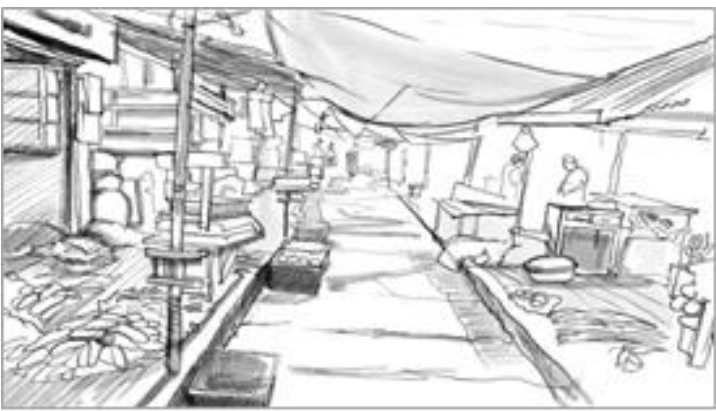

Figure 6: Displayable vending spaces

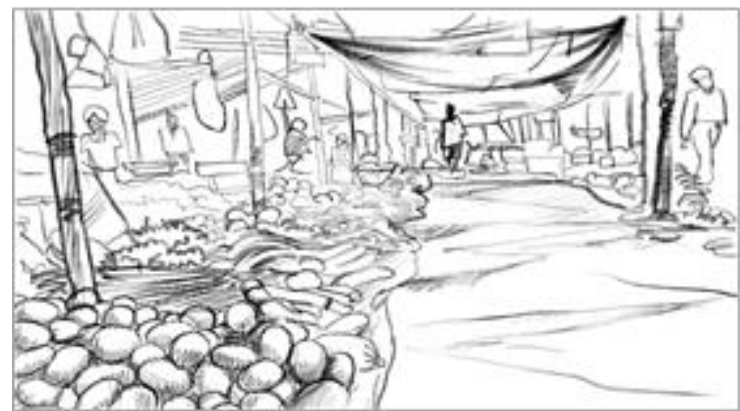

Figure 7: Comfortable walking lines

(Source: compiled by author 2020, based on secondary data)

The retail activities commence thereafter and the patrons start their engagements after the initial arrangements were complete. The users did not develop any psychological backwardness towards the internal space, even amidst a dusty atmosphere and muddy ground conditions, owing to the legible and mostly visually permeable physical strictures and the low scale built environment. The previous pola was the place to deal and interact with various social categories of people. Pola site was survived both rich and poor categories of sellers and buyers in an equal manner without any disturbances. The Pola Samithiya (the traders' association) was the main well-fare organization, which was represented by all the categories of vendors within the system. All income categories of sellers had equal opportunities and freedom to carry out their capable scale of vending activities.

\subsection{THE INTERVENTION OF THE AUTHORITY AND THE NEW MARKET BUILDING}

Under the 2008-2020 proposed revised Puttalam town center development plan, the UDA identified the central public market development project as a priority need for Puttalam town. On March 20th 2013, work started to establish the central public market building under the "RE-AWAKENING Project" by the Puttalam urban council. The previous pola site was selected as the prime location to build the central public market building. In 2013, the urban council demolished all the permanent and temporary structures on the pola site and established a one-story permanent building. In 2014, a newly built central public market building was opened by the Puttalam urban council to the public (UC2014). The main objective of the project was to strengthen the local economy with the infrastructure facilities. The new public market building was a more formal permanent building. It consisted of 225 sq. m gross flow area with 170 permanently partitioned shop units and 70 partially covered stall spaces.

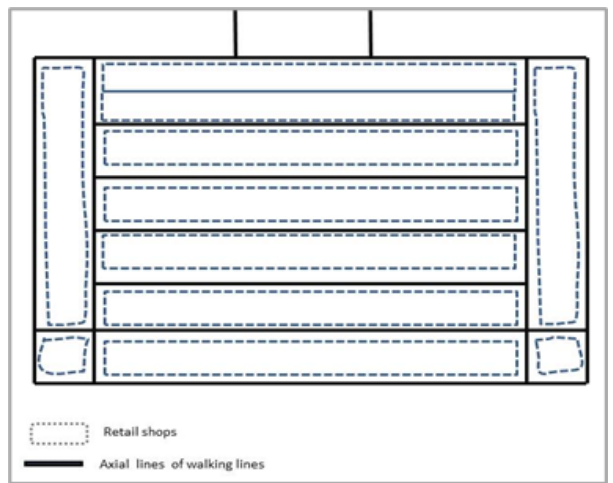

Figure 8: The Axial map of vending stall

segments in market building

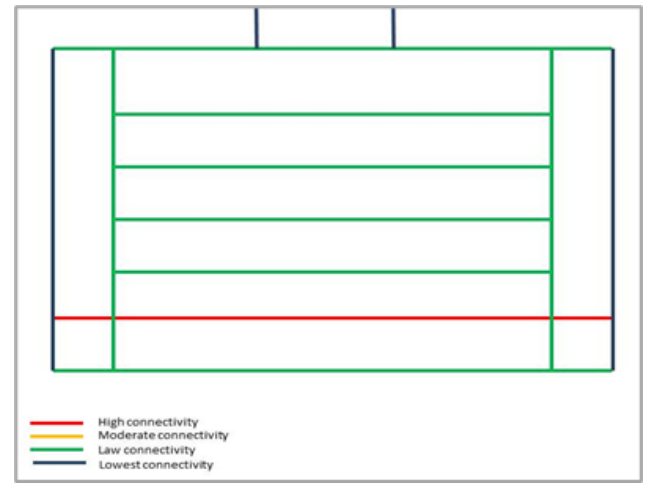

Figure 9: The Axial map of connectivity line in the Market building

In the allocation of spaces, the vendors who had their businesses in the existing Pola were given priority, in addition to 47 new vendors who were selected on varying criteria. The businessmen who had the interest and the capability to pay the rent prescribed by the urban council could obtain either a shop unit or a stall with an initial deposit with the urban council. Businesses from outside the community also 
had the opportunity to rent out shops and stalls from the market building. But the vendors who could not afford the initial payment and the rent and ones who were operating in the previous space on unofficial sub leases, by paying non-declared rents to third parties, lost space in the new arrangement. The narrow walking lines, structurally covered vending stalls and, the darkness of a inside market building created the distraction for the customers.
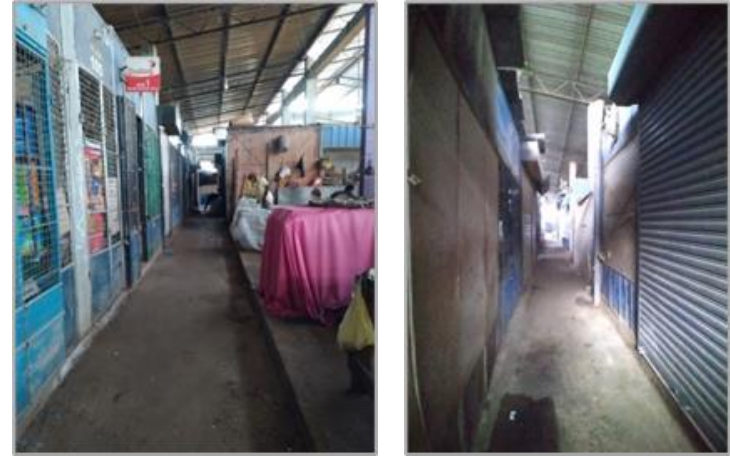

Figure 10: Structurally Covered Vending Stalls

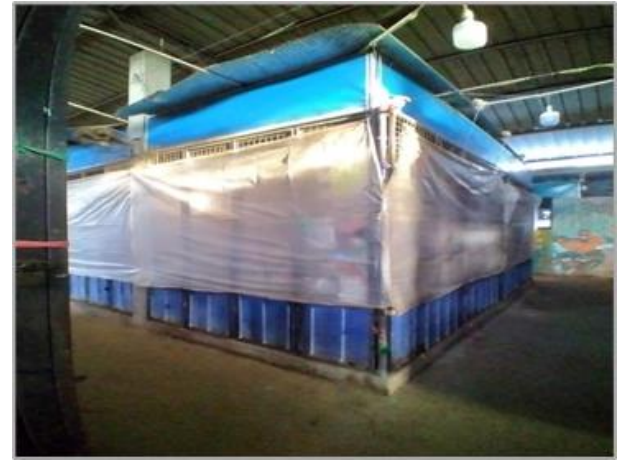

Figure 11: Narrow walking lines among vending stalls

(Source: compiled by author 2020, based on photography survey)

These vendors, who lost space within new premises, had organized as a community, and found space for their operations in strategic locations in Puttalam, encroaching the paved pedestrian area on either side of the Puttalam - Anuradhapura highway, Pauls Road, and Kotuwayaya Road in the vicinity of the main public bus terminal and the public market in the town.

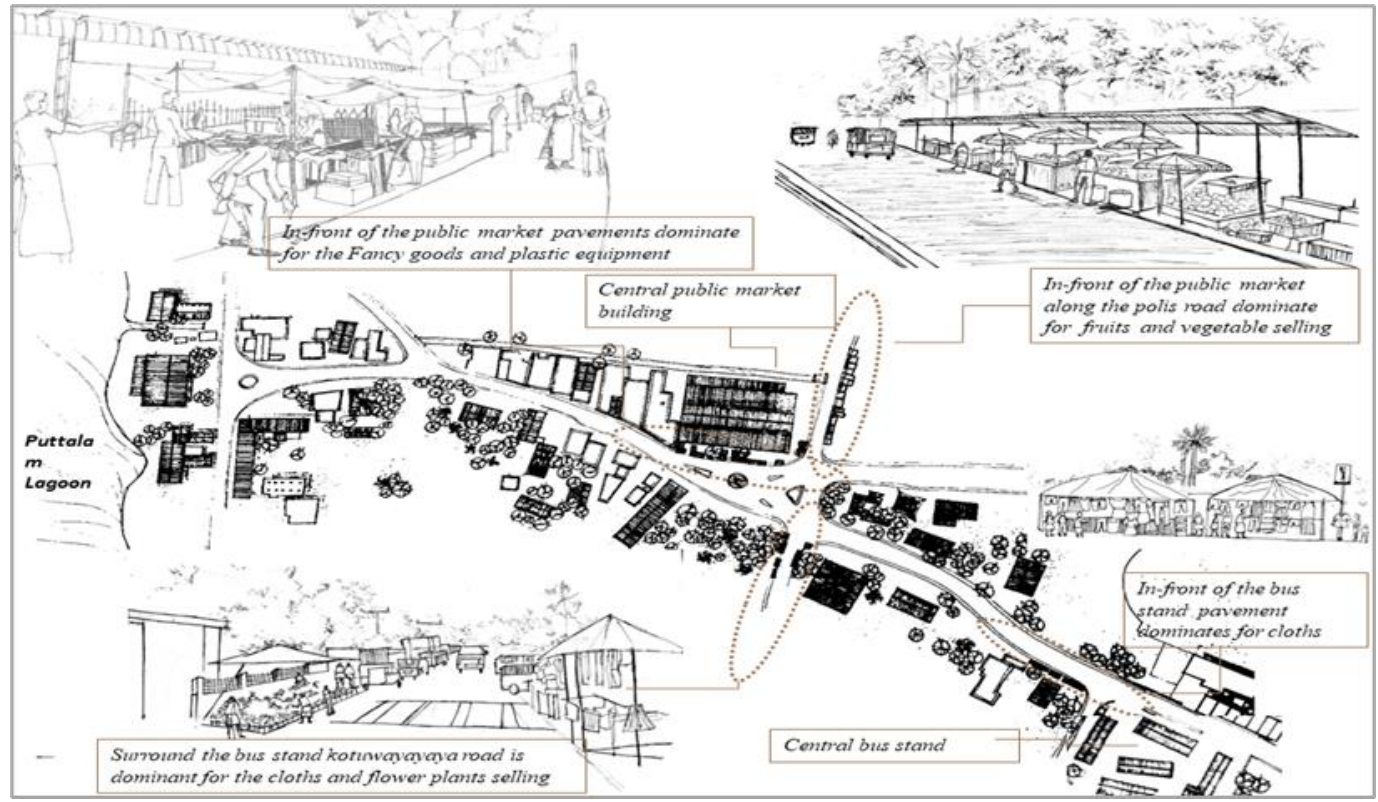

Figure 12: Space domination for various street vending types (source: Compiled by Author, 2020, based on field observations)

\subsection{THE CURRENT SITUATION OF INFORMAL VENDING SPACES}

Since the times that the new public market building was ceremonially opened and assigned to the local businessmen, a majority of the vendors who engaged in trading in vegetable and similar commodities have sold out their respective shop units and trade stalls to new parties and escaped into the street along with the other vendors. This had two consequences. On one hand, a large number of spaces in the new market building became vacant and lost crowds, and the increasing vacancies caused losses to the urban council. On the other hand, the public fare that was smoothly operating within the open ground of the town has now spilled over to the main street of the town, creating an observably chaotic situation. From time to time, the 
authorities evacuated the street vendors from the spaces that they 'illegally' occupied, but in all such instances, the vendors returned to the street, some times in a new order of arrangements.

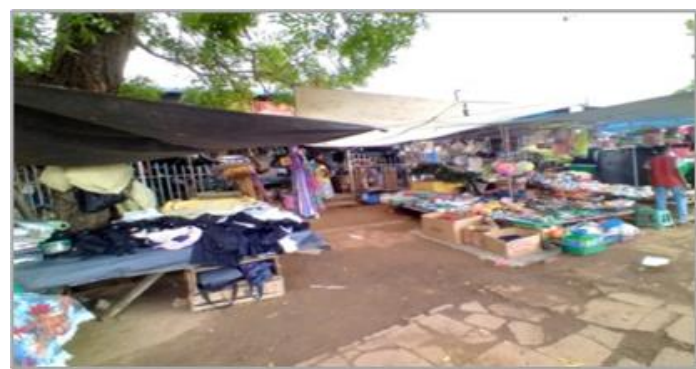

Figure13: Vending spaces are not disturbed to the formal market entrance

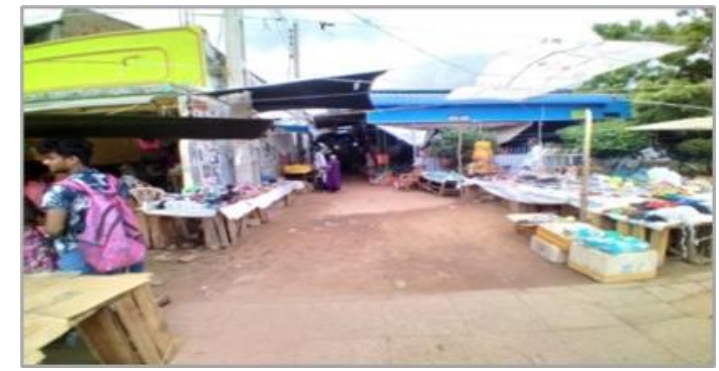

Figure 14: venders are tactful to reserve space for pedestrian flow

(Source: compiled by the author 2020, based on photography survey)

The pedestrian areas on the street have been negotiated by the vendors and the other users with no major complaints from any party, but their encroachment of the supposedly 'walking space' of the street and non-alignment with the legitimate order envisaged by the authorities in the public domain of the town, made them 'informal' and 'out of place' in the context of formal urban operations. Similar to the situations observed in the Pola space, the apparent physical structures assembled by the vendors were temporary, full of variety and incompatible with the formal built environments at their backdrop, for which they are also 'informal' in the urban planning and design context. Vendors formed those spaces in the pavement as temporary spaces using the temporary and fragile structures of huts, tents, and wood stands. Yet, in the ground layout, the space configuration was highly supportive of the transactions between the vendors and pedestrians. Vendors have appropriated their vending spaces with the main system of the area. Vendors have been building their vending spaces as displayable vending booths that customers can easily grasp. It is reasoned that because of the high level of customer attractions and to create a mindset among the neighbors that those vending spaces are an aspect of the community and should be within the town area. Vendors have been tactful to reserve small spaces for pedestrian traffic when they create their vending spaces because they are directly dependent on the pedestrians. Those informal vending spaces are formed by the vendors around 6.00 a.m. and have a high concentration of pedestrian flow. Before establishing the temporary installments, some of these spaces did not have any impression that those formal could convert to informal vending spaces. Venders who sold vegetables on previous pola sites have been tactfully adapted for the new vending types which have demand based on the selected spaces. When the UC evacuated their vending spaces from the pavements, vendors had to rebuild again and again in the same place.

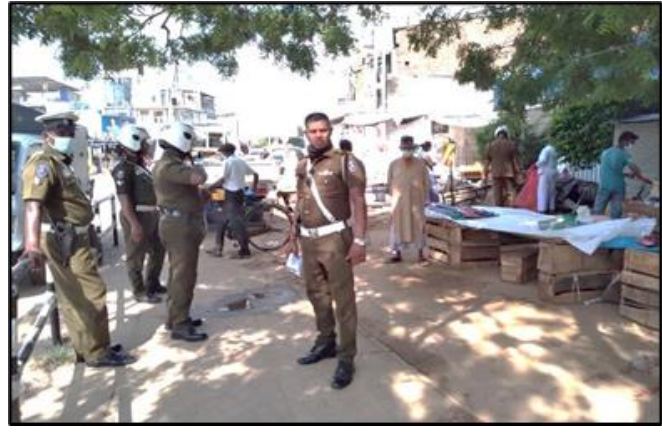

Figure15: eviction of the informal vending spaces around 9.00 a.m (2020.10.19)

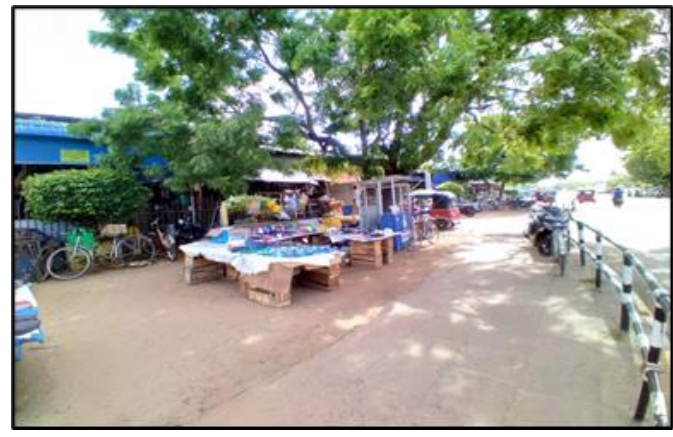

Figure16: vendors again rebuild space on same space 3.40 p.m (2020.10.19)

(Source: compiled by the author 2020.based on photography survey)

The self-built informal vending spaces were not merely physical entities, but facilitated a set of activities, interactions, and processes. The various activities of buying, selling, eating, drinking, walking, waiting, meeting, chatting, sharing information, and learning, and teaching, criticizing, gathering, protesting, and celebrating activities among a variety of social groups, made meaningful spaces around the public market area in Puttalam town. Puttalam town was emerging as a multi-cultural race society with the manifestation of Muslim culture, which peacefully engaged with Sinhala and Tamil society. The most significant character of the informal vending process is that vendors who lost their previous vending spaces 
from pola sites have organized themselves in to an informal vending community without any cultural degradation. The Muslim, Tamil and Sinhala vendors have built their vending spaces near to one another.

According to responder, the vendor who is now selling the fruits in front of the public market building explains his experience about their neighboring informal vendors.,

"I know many sellers. There are Muslim and Tamil sellers also. Most of wholesalers and "Nattamis" are Muslim. But all of us do not have a clash. Sometime my Tamil friend keep vending place when I am late to come"

Those informal vending spaces have increased unity of the community groups against to the Government interventions to remove their vending places.it have increased the relationship and organizational capacity of all the ethnic cultural groups.

According to responder, the vendor who is now selling banana on the pavement in in-front of the public market building explains her experience on unity of their informal vending community,

"Yes, we have that kind of organization. After they told us to go to the new market building all the Sinhala, Tamil, and Muslim vendors, we went to meet the mayor and told our difficulties. We wrote a letter and submit to UC by requesting to sell goods in the pavement."

The self-built informal vending spaces have become Peoples' places. It secures the vendors' freedom and their right to have their own daily income mechanism. The self-built informal vending places have secured equal rights and freedom for all Ethnic groups, and gender groups and equal groups. Most of the women are selling specially fruits, cloths, and pot hubs in front of the public market building and along the Colombo-Kurunegala main road.

According to responder 05, a vendor who is now selling banana in pavement of in-front of public market building explains her experience on previous pola site

"I and my husband live by selling banana. Some days my husband don't come here because he go to get medicine for diabetic.in those days I come alone. Other sellers normally help me to build my vending stall. There are more than thirty women who selling goods here there is no problem from others.

Those self-built informal vending spaces have become a significant economic and social system which has offered and umbrella of opportunities for all the social and cultural groups in Puttalam town. The informal vending spaces have been created another form of built and social cultural environment, as a meaningful people's place.

\section{Understanding of the Transformation of pola site into informal vending spaces through Self- Organizing theory}

The Pola can be understood as a unique local socio-economic system, which has evolved over time into an irreplaceable process of transactions of commodities between the vendors and the consumers. Typical selforganizing systems evolve towards a state of equilibrium and stable stage through spontaneous order. The internal agents build structures within the system to enable smooth transactions among its agents and for its own sustenance. The order of the operations in the Pola space resonated with a self-organized system, in which retailers and customers were the primary agents. There might have been various small scale service providers, informal rent collectors, beggars, and many others, integrated into the system and finding their livelihood from such engagements. The system is connected to the outer context with the wholesale suppliers, sanitary inspectors, regulatory officials, etc. The actors, both the vendors and other users, appropriated the formal shed space given by the authorities by means of extended shelters, tents, etc., assembled into the permanent structures. Such spatial arrangements were mutually accepted by the retailers and the buyers and courteously negotiated among them. In this manner, all actors found comfort for operations through organically evolved, but well-configured space, ample opportunities to offer and be offered goods and services, but in tight spaces, and mutually agreed, but unwritten rules and agreed patterns of behavior. This complex arrangement of the agents and their inter-relationship in Pola had been operating in harmony resonating the state of equilibrium. This equilibrium was disturbed when the external force, i.e., government authorities intervened with the implementation of the Central Public Market development project in the Pola land. From one side, the new Central Market building replaced the 
visually permeable, legible, adaptive, and informal physical environment supportive to the smooth operations of the Pola system, with a modern, rigid, and formal permanent arrangement. This new environment was not favored by vendors both for the reasons of affordability and for its incompatibility with the style of operations of their businesses. Thus, they became an 'out of place' community and excluded from the formal arrangements of the town. Therefore, they organized as an informal vending community to find an alternative means of sustaining their operations within the town environment. In choosing the new location, the mutual inter-relations between the vendors and the patrons was the decisive factor and thus, compelled to negotiate a portion of the space provided for the comfort of the pedestrians, who made up the major share of the patrons. This space appropriation process was physically reinforced with temporary and extended arrangements similar to what they had in the Pola space, but retaining the higher purpose: the walking of the pedestrians.

In this manner, the formation of informal vending spaces in formal urban spaces can be understood as an outcome of the self-organization of the retail vendors and the patrons of the place. However, there are some of the differences between the self-organized typical system and the pola system. Typical selforganized systems freely float after the adaptations to symmetric break. But as a socio-spatial system, the Pola exhibits a dynamic behavior based on varying interests, intensions, and the perceptions of its actors.

\section{Conclusion and Recommendations}

The case presented in this paper touched on the less explored knowledge of the peoples' processes of the production of informal spaces in the formal built environments, making references to the evolutionary process of informal street vending spaces in Puttalam town in Sri Lanka. Employing the concept of a selforganizing system, the formation, organization and the continuation of informal retail spaces in the formal urban environments, mutually coordinating with the patrons of the place and amidst interventions and intimidations of the authorities were disused. The study was based on both the recorded information on acts events, and the narratives of the actors.

By referring to the spatial configurations in different stages of evolution, the paper attempted to identify the manifestations of self-organized situations in the market place. The typical ecosystem is studied as the organized collection of parts of interactions or interrelated entities that form a unified whole. When it comes to the contemporary urban context there are identified unique urban sub-systems that are capable to stabilize their functionality through self-organization within the mainstream urban context. System structures are constructed by the internal agents of the system to stabilize the good fit of functionality and interactions within the system. But when the external forces intervene and disturb the structures and functions of the system, internal agents implement the spontaneous adjustments or rearrangements to reorganize the system balance while establishing the new patterns. In the urban context, informal urban spaces represent those self-organized new patterns which reflect the vitality, equity, and sustainability in the formal urban environment, and a good fit between structures and functionality. There may be many other self-organizing systems in a given urban environment, which are not apparent within the scope of this study but may be studied by other research attempts. At the same time, the behavior and the responses to external interferences of the identical agents apparent in this study can be different in other situations and the spaces produced may also show many differences.

The understanding of the informal space formation process provides a valid resource for planners to strengthen institutionalized planning practices. Since similar studies are limited in the Sri Lankan context, this study can be useful for such strengthening of the planning process. Urban planning and design interventions usually envisage static end states, idealized within planning and administrative concerns, but failed to achieve such ideal states in reality. The mostly overlooked and unnoticed actors in urban environments are actively engaged in constructing systems to balance the impacts of dominant planning and design interventions in the formal built environment and sustain them through self-organization. Hence, the timely attention of the decision-makers is required to understand and integrate the subtle ground realities and the peoples' processes into planning for the planning, designing and implementation of sustainable urban areas.

\section{References}

Anon., 2000. The control of "public" space:Conflict Over the Definition and Use of Verandah. In YEOH, B.S.A. CONTESTING SPACE:POWER RELATIONS AND THE URBAN BUILT ENVIRONMENT IN COLONIAL SINGAPORE. Oxford university press. pp.242-71.

Ashby, W.R., 2004. Principles of the self-organizing system. The Journal of General Psychology, pp.121-26. 
Babere, N.J., 2016. Social Production of Space: "Lived Space” of Informal Livelihood Operators; the Case of Dares Salaam City Tanzania. Current Urban Studies, pp.286-89.

Bailey, K.D., 1994. Sociology and the New Sytems Theory:Towards a Theoratical Synthesis. New York: State of New York Press.

Boelens, B.B.a., 2011. Self-organization in urban development: towards a new perspective on spatial planning. Cousins, M., 1994. The ugly. AA files, Autumn, pp.61-64.

Cresswell, T., 1996. In Place/Out of Place: Geography, Ideology, and Transgression. (Minneapolis: University of Minnesota Press.

Creswell, J.W., 2013. Qualitative Inquiry \& Research Design: Choosing Among the Five Approaches. Thousand Oaks, CA: SAGE Publications, pp.77-83.

Douglas, M., 1966. purity and danger:An Analysis of Concept of Pollution and Taboo. New York: Routledge.

Dovey, K., 2012. Informal urbanism and complex adaptive assemblage. InternatIonal Development plannIng revIew, pp.372-89.

Ellickson, R.C., 1996. Controlling chronic misconduct in city spaces: of panhandlers, skid rows, and public-space zoning. The Yale Law Journal, pp.1165-248.

Gehl, , 1936. LIFE BETWEEN BUILDINGS :Using Public Space. London: ISLAND PRESS.

LEFEBVRE , H., 1991. The Production of Space. Oxford: Basil Blackwell Ltd.

Liyanage, N., 2016. People's Neighborhood Center: Handiya in Sri Lanka. In Nihal \& Perera, N. People's space.

Maxwell, J.A., 1994. Qualitative Research Design: An Interactive Approach. Thousand Oaks, CA: SAGE Publications, Inc, pp.135-36.

Munasinghe, J., 2012. PLANNING AND SELF-ORGANIZING-The case of small towns in Sri Lanka. In Perera, N.

Transforming Asian Cities. pp.208-21.

Perera, N., 2009. PEOPLE'S SPACES: FAMILIARIZATION, SUBJECT FORMATION AND EMERGENT SPACES IN

COLOMBO. Planning Theory, pp.51-75.

perera, N., 2009. seeing and engaging people's space :Depriviation and challenges. In Perera, N. People's space. :

Perera, N., 2016. Production of Social Space: From Coping with Provided and Imposed Spaces to Creating Their Own Their Own. In Perera, N. People's places;Camiliariing:Creating. New York: Routledge. pp.217-38.

Perera, N., 2016. Production of Social Space: From Coping with Provided and Imposed Spaces to Creating Their Own Their Own. In Perera, N. People's space. Research Gate. pp.218-38.

Portugali , J., 1997. SELF-ORGANIZING CITIES. Pergamon , pp.353-80.

Portugali, J., 2011. Complexity, Cognition and the City. New York, Heidelberg, Berlin.

Roo, G.d., 2016. Self-organization and Spatial Planning :Foundations, challenges, constraints and consequences.

InPlanning, pp.1-55.

w.Soja, E., 1996. Thirdspace: Journeys to Los Angeles and Other Real-and-Imagined Places. Wiley-Blackwell: ISBN: 9781-557-86674-5. 